\title{
Detección de Citomegalovirus por PCR en tiempo real en sangre de lactantes menores, Paraguay 2015-2017
}

\author{
Detection of Cytomegalovirus using real-time PCR in the blood of \\ younger infants in Paraguay 2015-2017
}

\author{
Carmen Portillo ${ }^{1}$, Gloria Samudio ${ }^{2}$, Lidia Ortiz ${ }^{3}$, Pasionaria Ramos ${ }^{1}$
}

\section{RESUMEN}

Introducción: La infección por el Citomegalovirus (CMV) es frecuente en los primeros años de vida en los países subdesarrollados y en estratos bajos de los países desarrollados. Objetivo: conocer la prevalencia de infección por CMV con la identificación del genoma viral del Citomegalovirus por PCR en sangre, de lactantes de 0 a 12 meses de edad hospitalizados en la unidad cuidados intensivos con sospecha de infección. Materiales y Métodos: Estudio observacional descriptivo retrospectivo de corte transverso. En el periodo comprendido entre Enero del 2015 a Mayo de 2017, se analizaron muestras de sangre periférica de lactantes con sospecha de infección por CMV. Se utilizó reactivos Promega ${ }^{\circledR}$, seguido de una PCR en tiempo real en equipo Rotor Gene®. Variables: edad, sexo, procedencias, síntomas clínicos y resultados de la reacción en cadena de la polimerasa. Los datos fueron analizados utilizando estadísticas descripticas y analíticas. Resultados: se incluyeron 146 resultados de PCR en tiempo real en sangre, el 84\% (123/146) eran lactantes menores de 6 meses. En el 42\% (62/146) se detectó el ADN viral por PCR, de estas $38 \%$ fueron niñas; $28 \%$ en lactantes menores de 2 meses. El 17,7\% (11/62) fueron neonatos prematuros. Los síntomas clínicos incluyeron hallazgos clínicos en los casos positivos fueron Prematuridad, anemia en un $8 \%$ Ictericia $5.6 \%$, dificultad respiratoria $5.4 \%$, neumonía $1.3 \%$, Hepatoesplenomegalia 4\%. Conclusión: Se confirmó infección por CMV mediante PCR en tiempo real en $42 \%$ en Lactantes menores, $28 \%$ de entre 0 a 2 meses y $17,7 \%$ en prematuros, similar a otras casuísticas.

Palabras claves: Citomegalovirus, Reacción en cadena de la polimerasa, lactantes, infección congénita.

\section{ABSTRACT}

Introduction: Cytomegalovirus (CMV) infection is frequent during the first years of life in underdeveloped countries and in lower socioeconomic groups. Objective: to determine the prevalence of CMV infection identifying the viral genome of Cytomegalovirus by using PCR in blood samples from infants from 0 to 12 months of age who were hospitalized in the intensive care unit with a suspected infection. Materials and methods: This was a retrospective, descriptive, observational and crosssectional study. From January 2015 to May 2017, we analyzed peripheral blood samples from infants with suspected CMV infection. Promega ${ }^{\circledR}$ reagents were used, followed by real-time PCR with Rotor Gene ${ }^{\circledR}$ equipment. Variables were: age, sex, place of origin, clinical symptoms and results of the polymerase chain reaction. The data was analyzed using descriptive and analytical statistics. Results: 146 real-time PCR results from blood samples were included, $84 \%(123 / 146)$ were infants under 6 months of age. In $42 \%$ (62/146) viral DNA was detected by PCR, of these, $38 \%$ were girls; $28 \%$ were infants under 2 months of age. $17.7 \%(11 / 62)$ were preterm infants. Clinical symptoms and findings in the positive cases were prematurity, anemia in $8 \%$ Jaundice in $5.6 \%$, respiratory difficulty in $5.4 \%$, pneumonia in and $1.3 \%$, and hepatosplenomegaly in $4 \%$. Conclusion: CMV infection was confirmed by real-time PCR in $42 \%$ of infants, $28 \%$ were between 0 to 2 months of age and $17.7 \%$ were preterm infants, similar to other studies.

Keywords: Cytomegalovirus, polymerase chain reaction, infants, congenital infection

${ }^{1}$ Laboratorio "Carmen Portillo". Asunción, Paraguay.

${ }^{2}$ Instituto de Previsión Social, Hospital Central, Servicio de Infectología. Asunción, Paraguay.

${ }^{3}$ Ministerio de Salud Pública y Bienestar Social, Hospital Nacional de Itauguá. Itauguá, Paraguay.

Correspondencia: Dra. Carmen Portillo; Correo: portillolab@gmail.com

Conflicto de interés: Los autores declaran no poseer conflicto de interés

Recibido: 03/10/2018. Aceptado:16/04/2019

DOI: https://doi.org/10.31698/ped.46012019005 


\section{INTRODUCCIÓN}

La infección por el Citomegalovirus (CMV) es frecuente en los primeros años de vida en los países subdesarrollados y en estratos bajos de los países desarrollados. El CMV constituye, en la actualidad, la primera causa de infección intrauterina asociada a malformaciones congénitas ${ }^{(1)}$. La trasmisión materno fetal puede ocurrir durante la enfermedad aguda o reactivación de infección pasada de la madre. De todos los recién nacidos afectados por el virus un 10 a $15 \%$ serán sintomático. La infección puede adquirirse de forma vertical (transplacentaria); un $5 \%$ durante el pasaje a través del canal del parto y durante la etapa postnatal precoz mediante la lactancia materna $(60 \%)$ o transfusiones sanguíneas ${ }^{(2)}$.

Los síntomas de infección son diversos: bajo peso al nacer, hepato -esplenomegalia, trombocitopenia, microcefalia y trastornos neurológicos. La infección congénita por CMV se asocia a discapacidad permanente, siendo la primera causa de hipoacusia neuro-sensorial (HNS) no genética (15 a $25 \%$ ) y retraso psicomotor ${ }^{(1)}$. La importancia de una detección temprana y precisa de la infección por el $\mathrm{CMV}$, permite iniciar el tratamiento con ganciclovir intravenoso durante 6 semanas a fin de prevenir el desarrollo de hipoacusia progresiva, así como las alteraciones en el lenguaje y aprendizaje, en los niños con infección congénita sintomática por $\mathrm{CMV}^{(3,4)}$. De no recibir tratamiento, hasta un $87 \%$ de los niños afectados congénitamente, pueden desarrollar discapacidad auditiva.

En pacientes hospitalizados la primo infección o reactivación, se confirma por la presencia de los síntomas en el paciente y estudios de laboratorio específicos que detectan las partículas virales en circulación como la PCR o el aislamiento viral en cultivos celulares ${ }^{(1)}$.

La infección congénita por CMV se confirma cuando se aísla el virus de la orina o saliva en las 3 primeras semanas de vida. El virus adquirido a través de la leche materna, probablemente tiene poco impacto en niños a término, pero si en los prematuros, ya que puede afectar su desarrollo neurológico a largo plazo $^{(1)}$.
Los recién nacidos infectados por $\mathrm{CMV}$, cualquiera sea la vía de contagio, pueden excretar el virus, incluso hasta el año de vida (8-60\%). Si el virus en orina se detecta luego de las tres semanas de vida, resulta difícil establecer si se trata de infección connatal o adquirida ${ }^{(5)}$. La excreción viral prolongada se asocia a infección post natal, adquirida en el canal del parto o por leche materna ${ }^{(6)}$. El cultivo rápido del virus a través de la técnica de Shell vial, permite la detección del CMV en orina; sin embargo esta técnica es laboriosa y compleja, por lo que actualmente no constituye el método de primera elección para el diagnóstico ${ }^{(7)}$.

La técnica de reacción en cadena de la polimerasa (PCR), que surgió como una alternativa diagnóstica válida, se realiza en orina, sangre, LCR y saliva en el recién nacido como prueba de tamizaje. En la actualidad la PCR se constituye en el standard de oro, al detectar la región constante ApoB del genoma viral, con buen nivel de sensibilidad, aunque la detección, no siempre implica replicación viral. Sin embargo esta sensibilidad es menor en saliva y LCR debido a la baja excreción viral ${ }^{(5)}$.

La prevalencia a nivel mundial de infecciones congénitas por $\mathrm{CMV}$, oscila de entre 0.5 a $2.4 \%$ en recién nacidos vivos, 5 a $10 \%$ en lactantes infectados in útero, con tasas de 0.5 a $1 \%$ en USA y de 0.3 a $0.6 \%$ en Europa ${ }^{(3)}$. En Latinoamérica algunos datos de prevalencia de CMV en menores revela: $83 \%$ en Venezuela ${ }^{(3)}$, en Chile $1.7 \%{ }^{(8)}, 0.5$ a $2.4 \%$ de $R N$ vivos en México $^{(9)}$, un $90 \%$ de infección primaria en menores de 18 años en $\mathrm{Cuba}^{(8)}$ y $52 \%$ en nuestro país por PCR también en menores de 18 años ${ }^{(10)}$.

En el país no existen reportes de prevalencias de la infección por CMV en lactantes menores.

El objetivo del presente estudio fue conocer la prevalencia de infección por CMV con la identificación del genoma viral del Citomegalovirus mediante la Reacción en Cadena de Polimerasa (PCR) en lactantes de 0 a 12 meses con sospecha de infección congénita, admitidos en hospitales de referencia del departamento central de la República del Paraguay. 


\section{MATERIALES Y MÉTODOS}

Estudio observacional, descriptivo, transversal y retrospectivo realizado con muestras sanguíneas provenientes de pacientes hospitalizados en centros públicos y privados de Asunción y Departamento Central. Realizado en el periodo de enero del 2015 a Mayo de 2017.

Fueron ingresados al estudio todos los pacientes de 0 a 12 meses de edad con sospecha de infección sintomática congénita o adquirida por CMV, por historia prenatal o serología materna sugerente de infección primaria, procedentes de salas de cuidados intensivos. Fueron excluidas las muestras sanguíneas consideradas deficientes por cantidad o por trasporte inadecuado, que pudieran comprometer los resultados. Las variables estudiadas fueron edad en meses, procedencia, signos y síntomas y resultados de la PCR para CMV.

Los datos de los pacientes fueron registrados en una hoja de captación de datos confeccionada especialmente para el efecto. Las hojas de captación y las muestras sanguíneas con EDTA de los pacientes, fueron remitidas a un laboratorio de referencia de virología y procesadas por un especialista del área.

La extracción del ADN se realizó con el Kit comercial Promega ${ }^{\circledR}$, acorde a las instrucciones del fabricante seguido de una PCR en tiempo real. Este último método se realizó de acuerdo al protocolo modificado de Casas y Tenorio para la detección del gen de expresión temprana UL54, en el equipo Rotor Gene®. El volumen final de reacción fue de 20 ul, se utilizó una Master mix Sso Fast Eva Green Supermix de Bio $\operatorname{Rad}{ }^{\circledR}$, con una ronda de reacción de 35 ciclos de $94^{\circ} \mathrm{C}$ por $5 \mathrm{~min}, 94^{\circ} \mathrm{C}$ por $15 \mathrm{seg}, 49^{\circ} \mathrm{C}$ por $15 \mathrm{seg}$., $72^{\circ} \mathrm{C}$ por 15 seg. y una extensión final de $72^{\circ} \mathrm{C}$ por 5 min. Los primeros utilizados que detectan un producto de $78 \mathrm{pb}$ fueron sintetizados por Invitrogen ${ }^{\circledR}$. El límite de detección fue de 5 copias $/ \mathrm{ml}$, se utilizaron controles positivos y negativos de procedencia comercial Artus. ${ }^{\circledR}$ Los resultados se informaron Detectables y No detectables, previo análisis de la curva de meelting. El resultado detectable o positivo de la PCR para CMV se consideró indicativo de infección. La sensibilidad y valor predictivo negativo de la prueba es de $100 \%$, la especificidad de $78 \%$.

Para el análisis e interpretación de las variables, se transcribieron a una planilla electrónica en el formato Microsoft Excel 2010, utilizando la estadística descriptiva mediante el programa estadístico Epi Info.7® y expresados en tablas a manera de frecuencias absolutas y relativas.

\section{Aspectos éticos}

Se respeto en todo momento los principios éticos que rigen los estudios en seres humanos. Los padres firmaron el consentimiento informado para realización de prueba en materiales biológicos. Se respetaron los principios de beneficencia y justicia, no se realizó ninguna intervención y tampoco implicó ningún riesgo para los pacientes.

\section{RESULTADOS}

Se incluyeron los resultados de 146 muestras de sangre de niños de ambos sexos, menores de un año realizados por PCR en tiempo real para detección de CMV. Las características de grupo etario procedencia y prematurez se observan en la Tabla 1 De la población de prematuros, el 13,4\%(12/89), tenían antecedente de serología materna positiva para CMV.

En el 42,5\% (62/146) se detectó el ADN viral del CMV por la PCR. De los 62 casos positivos 35,4\% (22/62) fueron niñas, 53,3\%(33/62) niños, 11,3\%(7/62) sin datos en cuanto al sexo. Un $17,7 \%$ (11/62) fueron recién nacidos de pretermino, de los cuales $8 / 11$ eran hijos de madres con serología positiva para CMV y se considero como CMV congénito.

La prevalencia de casos positivos según grupo etario se encuentra en la Tabla 2.

Los principales hallazgos clínicos en los pacientes cuyas muestras fueron estudiadas por sospecha de infección por CMV se encuentran en la Tabla 3.

Entre los hallazgos menos frecuentes o indeterminados se reportaron fiebre, infecciones varias, sepsis. 
Tabla 1. Datos del grupo etario, procedencia y prematurez de los pacientes cuyas muestras de sangre fueron estudiadas, $\mathrm{N}=146$.

\begin{tabular}{lc}
\hline Grupo etario (Meses) & $\mathbf{N}(\%)$ \\
\hline $0-5$ & $123(84)$ \\
$7-12$ & $23(16)$ \\
\hline Procedencia & \\
Hospitales públicos & $141(97)$ \\
Hospitales privados & $4(3)$ \\
Prematuros & $89(61)$ \\
\hline
\end{tabular}

Tabla 2. Distribución etaria de las muestras, y resultados de PCR, de los lactantes hospitalizados con sospecha de infección por $\mathrm{CMV}, \mathrm{N}=146$.

\begin{tabular}{lccccc}
\hline & \multicolumn{2}{c}{ Positivo } & \multicolumn{2}{c}{ Negativo } & p \\
\hline Edad en meses & $\mathbf{N}$ & $\mathbf{\%}$ & $\mathbf{N}$ & $\mathbf{\%}$ & \\
$0-2$ & 41 & 28 & 28 & 19 & $<0.0001^{1}$ \\
$3-5$ & 7 & 4 & 47 & 32 & $<0.0001^{1}$ \\
$6-8$ & 4 & 3 & 3 & 3 & $<0.45^{2}$ \\
\hline $9-12$ & 6 & 4 & 4 & 3 & $0.20^{2}$ \\
Sin datos & 4 & 3 & 2 & 1 & \\
Total & $\mathbf{6 2}$ & $\mathbf{4 2}$ & $\mathbf{8 4}$ & $\mathbf{5 8}$ & $\mathbf{1 4 6}$ \\
\hline $1=x 2$ & 2= Test Fisher & & &
\end{tabular}

Tabla 3. Comparación de las características clínicas de los lactantes cuyas muestras fueron estudiadas para la detección de CMV por PCR, N=146.

\begin{tabular}{|c|c|c|c|c|c|}
\hline \multirow[t]{2}{*}{ Signos presentes } & \multicolumn{2}{|c|}{ PCR NEGATIVO } & \multicolumn{2}{|c|}{ PCR POSITIVO } & \multirow[t]{2}{*}{$\mathrm{p}$} \\
\hline & $\mathbf{N}$ & $\%$ & $\mathbf{N}$ & $\%$ & \\
\hline Ictericia & 18 & 12 & 8 & 5.6 & $<0.18$ \\
\hline Trastornos hematológicos* & 16 & 11 & 6 & 4 & $<0.11$ \\
\hline Anemia & 14 & 9 & 12 & 8 & $<0.67$ \\
\hline Dificultad Respiratoria & 10 & 6.8 & 8 & 5.4 & $<0.85$ \\
\hline Hepato-esplenomegalia & 6 & 4 & 6 & 4 & $<0.5$ \\
\hline Convulsiones & 6 & 4 & 1 & 0.7 & $<0.12$ \\
\hline Neumonía & 4 & 3 & 2 & 1.3 & $<0.64$ \\
\hline Microcefalia & 4 & 3 & 2 & 1.3 & $<0.64$ \\
\hline Cardiopatía & 2 & 1.3 & 2 & 1.3 & $<0.75$ \\
\hline Hidrocefalia & 2 & 1.3 & 0 & 0 & $<0.3$ \\
\hline Desnutrición severa & 1 & 0.7 & 1 & 0.7 & $<0.6$ \\
\hline
\end{tabular}

\section{DISCUSIÓN}

La prevalencia del Citomegalovirus en sangre en 42 $\%$ de nuestros pacientes hospitalizados en cuidados intensivos, en los cuales se estableció sospecha clínica, debe llamar la atención. Esta prevalencia en prematuros del $17 \%$, con un $28 \%$ en lactantes menores de 28 días, resulto ser más elevada que la reportada por otros autores ${ }^{(11,12)}$.
A pesar de que en la mayoría de los ingresados en el estudio, fueron menores de 2 meses 109 (75\%), de ellos, en el $28 \%$ que se detectó el CMV, se podría asociar a infección congénita. La concordancia de la serología materna con el PCR para CMV en el niño no fue estudiada, ya que es conocido que la serología posee baja sensibilidad y especificidad para detectar la enfermedad.

No pudimos precisar si la prevalencia alta se debe a que se incluyeron todos los niños hasta el año, o que la infección haya sido adquirida en forma horizontal a través de los meses de vida. En este punto, es importante mencionar que las trasfusiones sanguíneas recibidas, los recién nacidos para mejorar su estado crítico, pudieron haber contribuido también. Este hecho puede hacer que nuestra prevalencia resulte mucho mayor que el reportado por la literatura, que refiere hasta el $60 \%$ de niños con antecedentes de infección congénita por $\mathrm{CMV}$, pueden seguir excretando el virus por la orina hasta el año de edad ${ }^{(13)}$.

Por otro lado, este estudio pretendió establecer las prevalencias de la detección del CMV y no la causalidad de la enfermedad, ya que la sintomatología de los pacientes estudiados podría deberse a otro tipo de infecciones tales como sepsis o enfermedades del grupo STORCH ${ }^{(14)}$, que evaluados con el laboratorio y el resultado de PCR, posibilitaron tomar la mejor decisión terapéutica.

Aunque la prevalencia de $42 \%$ encontrada es elevada comparada con los citados precedentemente, creemos que la misma puede estar subestimada, ya que la viremia es oscilante en sangre, comparada con la mayor y persistente excreción viral que se observa en orina, que es la muestra de elección ${ }^{(15)}$.

Nuestra prevalencia en prematuros del $28 \%$ fue mayor a la casuística Española, que reporto un 10\% de confirmación del CMV mediante la PCR y antigenemia ${ }^{(16)}$. Aunque la PCR tiene 90 a $98 \%$ de sensibilidad y una especificidad de 92 a $98 \%$, detecta los virus circulantes a pocos días de haberse establecido la infección en los $\mathrm{RN}$ asintomáticos o con pocos síntomas, la sensibilidad puede variar o disminuir con cargas virales bajas ${ }^{(17,18)}$. Otras casuísticas reportan un $100 \%$ pero utilizando sangre 
seca ${ }^{(19)}$, resulta variable en otros materiales biológicos como sangre, orina, LCR y en saliva ${ }^{(11)}$. Otra muestra también utilizada es el humor acuoso, mediante la PCR en tiempo real que resultó ser un método simple de confirmación de sospecha de infección por CMV en la primera consulta oftalmologica ${ }^{(20)}$.

Las prevalencias varían con los diferentes estudios y países, así tenemos en Bolivia con solo el $0.6 \%$ de detección ${ }^{(13)}$ y con 28 a $34 \%$ en el grupo de Boppaana $\mathrm{y} \operatorname{cols}^{(21)}$. El estudio en Japón hecho en sangre y orina de niños con trastornos auditivos, demostró que la mayor carga carga viral no predice la aparición de Hipoacusia, pero si la excreción viral prolongada ${ }^{(22)}$. La asociación de Hipoacusia causada por CMV en esta casuística no pudo ser determinada, pero es recomendado el tamizaje de audición en los recién nacidos y lactantes a fin de diagnosticar esta afección en forma rápida ${ }^{(23,24)}$.

Existen diferentes tipos y marcas de reactivos para PCR en tiempo real ${ }^{(25)}$. Así el estudio multicentrico de Suresh y cols, realizado en Recién Nacidos, utilizando PCR en tiempo real con muestras de saliva liquida o seca, mostró sensibilidad, especificidad y valores predictivos positivos y negativos mayores al $90 \%$, por lo que esta muestra podría ser recomendada para su uso como tamizaje ${ }^{(26)}$. Un estudio en Atlanta encontró más detecciones del CMV en saliva que en orina ${ }^{(19)}$.

La manifestación más frecuente reportada en este grupo fue la prematuridad en un $17 \%$, superior a lo reportado por los mejicanos, con $15,3 \%$ en prematuros extremos con $2,3 \%$ confirmadas congénitas $^{(8)}$. La evaluación de niños prematuros extremos ( $<28$ semanas de edad gestacional) al nacer ayuda, para buscar la asociación al CMV, así como a diferenciar entre infección congénita y postnatal ${ }^{(27,23)}$.

De las madres con serología positiva para CMV, se detectó PCR en 8 de los RN (66\%). Sin embargo en este grupo de madres no se determinó si fue infección primaria o reactivación, siendo importante la prevención sobre todo en la seronegativas ${ }^{(16,28)}$. Aunque de un 70 a $88 \%$ de madres seropositivas que son excretoras de CMV por leche, solo $10 \%$ de los $\mathrm{RN}$ amamantados desarrollaran infección clínica aparente ${ }^{(20)}$, pero esta fuente de infección post natal, no lo hemos podido investigar ${ }^{(29)}$. La seroprevalencia que fue similar en madres excretoras o no, en el estudio en niños sanos en Atlanta, no permite considerarlo como un valor predictor ${ }^{(24)}$.

Varias debilidades pueden apuntarse en este estudio, tal como la falta de comparación con PCR realizado en orina (donde la viremia es constante), el gold estándar a fin de obtener sensibilidad y especificidad de la técnica utilizada ${ }^{(26)}$.

Por otro lado, es importante considerar que debido al estado de latencia y cronicidad que produce el $\mathrm{CMV}$, no siempre se puede relacionar la infección activa detectada por técnicas moleculares con enfermedad, con lo cual, algunas de las detecciones de CMV pudieron haber sido solo excreción viral y no infección activa. Por ello hubiera sido importante el seguimiento de estos casos para evaluar el rol etiológico del CMV con los hallazgos clínicos además de una carga viral o un control post tratamiento en relación a los trastornos auditivos o neurológicos causados por el virus. Esta cuantificación para el CMV, también es recomendada cuando se evalúan a bebés sin ninguna otra manifestación de enfermedad por $\mathrm{CMV}^{(14)}$.

\section{CONCLUSIÓN}

Este estudio estableció una prevalencia de $42 \%$ de detección de infecciones congénitas atribuidas al CMV mediante la PCR en tiempo real en nuestro país, con muestras de sangre de los niños hospitalizados en cuidados intensivos en servicios de salud de capital y departamento central con la sospecha clínica, concentrándose los resultados positivos en los menores de 28 días $(28 \%)$ y con diagnóstico de prematurez (17\%).

\section{AGRADECIMIENTOS}

A la Dra. Romina Samudio Rojas por su ayuda con el registro de datos y los gráficos. 


\section{REFERENCIAS BIBLIOGRÁFICAS}

1. Baquero-Artigao F, Grupo de estudio de la infección congénita por citomegalovirus de la Sociedad Española de Infectologia Pediátrica. PEDIATRIA: Documento de consenso de la Sociedad Española de Infectologia Pediátrica sobre el diagnóstico y el tratamiento de la infección congénita por citomegalovirus. An Pediatr (Barc). 2009; 71 (6):535-547.

2. Chacón M, Castillo de Febres OT, de Naveda M, Castro L, Cassanova de Escalona L, Flores Chávez ME. Despistaje de infección por Citomegalovirus en niños VIH positivos mediante PCR: relación con la serología y evolución clínica. Archivos Venezolanos de Puericultura y Pediatría. 2007;70(3):76-80.

3. Reyes Romero H, Navarro Rojas P, Suárez Cedraro D, de la Parte MA, Reyes Barrios H. Infección por Citomegalovirus: aspectos diagnósticos y terapéuticos. Informed. 2013; 15(3):105-112.

4. Nishida K, Morioka I, Nakamachi Y, Kobayashi Y, Imanishi T, Kawano S, et al. Neurological outcomes in symptomatic congenital cytomegalovirus-infected infants after introduction of newborn urine screening and antiviral treatment. Brain Dev. 2016;38(2):209-16.

5. Carballal G, Videla C. Citomegalovirus humano (herpesvirus humano 5 o HHV-5). En: Carballal G, Oubiña JR. Virología Médica. 4 ed. Argentina: Corpus; 2015. p. 404-14.

6. Espinosa-Sotero MC, Tecuatl BL, Saltigeral P. Infección congénita por Citomegalovirus. Rev. De Enf. Inf. En Ped. 2012; XXVII(102):1-2.

7. Ligozzi M, Poggi M, Saletti M, Gibellini D. Development of a real-time quantitative polymerase chain reaction assay for the detection of congenital human cytomegalovirus infection in urine samples. Mol Cell Probes. 2016;30(1):50-2.

8. Noyola, D, Matienzo-Serment L, Rodríguez-Vidal SO, Ochoa-Pérez UR, Piña-Granja JM, García-Sepúlveda CHA. Infección congénita por Citomegalovirus en recién nacidos del estado de San Luis Potosí, México. Salud pública de México. 2011;53(6)513-15.

9. Correa Sierra C, Kourí Cardellá V, Pérez Santos L, Alemán Campos Y, Soto Brito Y, Álvarez López A, et al. Infecciones por virus de Epstein-Barr y Citomegalovirus en pacientes con síndrome mononucleósico. Panorama Cuba y Salud. 2013; 8(3):15-20.

10. Portillo C, González D, Núñez D, Benitez G. Citomegalovirus en pacientes inmunocomprometidos detectados por PCR en Paraguay del 2008 al 2015. Rev. virtual Soc. Parag. Med. Int. 2016;3(2):77-84.

11. Reina J, Weber I, Riera E, Busquets M, Morales C. Utilidad de una técnica de Reacción en Cadena de la Polimerasa (PCR) cuantitativa en tiempo real en el diagnóstico de infección congénita y posnatal por citomegalovirus. Anales de Pediatría. 2014; 80(5):275-340.

12. Luck S, Wieringa JW, Blázquez-Gamero D, Henneke P, Schuster K, Wieringa JW, Blázquez-Gamero D, Henneke $\mathrm{P}$, Schuster K, et al. Congenital Cytomegalovirus: a european expert consensus statement on diagnosis and management. The Pediatric Infectious Disease Journal. 2017;36 (12):1205-1213.

13. Gutiérrez Salinas J, Carmona García R, Cruz Tovar L. Concentraciones de IgG e IgM en pacientes con infección por Citomegalovirus diagnosticada mediante PCR cualitativa. Med. Int. Mex. 2009; 25(2):105-10.

14. Reina Prieto J. Estudio prospectivo sobre la eficacia de una PCR múltiple en el diagnóstico de las infecciones causadas por los herpesvirus. Medicina Balear. 2011; 26(2);20-26.

15. Marsico C, Kimberlin D. Congenital Cytomeglovirus infection: advances and challenges in diagnosis, prevention and treatment. Italian Journal of Pediatrics. 2017; 43:381-8.

16. Reina Prieto J, Balliu P. Primoinfeccion postnatal por CMV asociada a lactancia materna en pacientes de riesgo. Rev. Esp Pedia. 2012; 68(5):344-51.

17. Farfán M, Torres J, Vergara A, Donoso G, Alba A, Paris $\mathrm{C}$, et al. Comparación de las técnicas de reacción de la polimerasa en cadena en tiempo real y antigenemia para detección de Citomegalovirus en niños sometidos a trasplantes. Rev. Chil. Infect. 2011;28 (2):113-17.

18. Ebrahimi-Rad M, Shakeri TS, Shirvani F, Shahrokhi K, Shahrokhi N. Prevalence of congenital cytomegalovirus infection in symptomatic newborns under 3 weeks in Teheran. Iran BMC Infectious Diseases. 2017; 17(1):688.

19. Cannon MJ, Stowell JD, Clark R, Dollard PR, Johnson D, Mask K. et al. Repeated measures study of weekly and daily cytomegalovirus shedding patterns in saliva and urine of healthy cytomegalovirus-seropositive children. BMC Infectious Diseases. 2014, 14: 569-79.

20. Miyazaki D, Shimizu D, Shimizu Y, Inoue Y, Inoue T, Higaki S, et al. Diagnostic efficacy of real- time PCR for ocular cytomegalovirus infections. Graefes Archive for 
Clinical and Experimental Ophtalmology. 2018; 256:24132420.

21 Amin MM, Stowell JD, Hendley W, Garcia P, Schmid DS, Cannon MJ, et al. CMV on surfaces in homes with young children: results of PCR and viral cultures. BCM InfectiousDiseases. 2018;18(1):391 1:7.

22. Kawada J, Torii Y, Kawano Y, Suzuki M, Kamiya Y, Kotani $\mathrm{T}$, et al. Viral load in children with congenital cytomegalovirus infection identified on newborn hearing screening. Journal of clinical virology. 2015; 05:41-45.

23. Avendaño F, Ferres M, Spencer E. Virología Clínica. Chile; Mediterraneo; 2011.p. 223-31.

24. García-Vicario F, Benito Orejas JI, Valda Rodrigo V, Navazo Eguía AI. Cribado auditivo neonatal nuestra experiencia y planteamientos de futuro. Rev. Soc. Otorrinolaringol Castilla León Cantab La Rioja. 2014; 5(13):100-111.

25. Cofré F, Delpiano L, Labraña Y, Reyes A, Sandoval A, Izquierdo G. Síndrome de TORCH: enfoque racional del diagnóstico y tratamiento pre y post natal: recomendaciones del Comité Consultivo de Infecciones Neonatales Sociedad Chilena de Infectología 2016. Rev.Ch. Infectol 2016;33(2):191-216.

26. Cannon M, Hyde T, Scott Schmid D. Review of cytomegalovirus shedding in bodly fluids and relevance to congenital cytomegalovirus infection. Rev Med Virol. $2011 ; 21(4): 240-255$.

27. Botet F, Figueras Aloy J, Álvarez E, de Alba C, Dorronsolo I, Echaniz Urcelay I, et al. Cribado universal de infección por citomegalovirus en prematuros de menos de 1.500 g. An Pediatr (Bar). 2014; 81(4):203-272.

28. Mack I, Burckhardt MA, Heininger U, Prufer F, Wellmann S. Symtomatic congenital CMV infection after recurrent maternal infection. Australia: Swiss Society of Neonatology; 2017.

29. Mussi-Pinhata MM, Yamamoto AY, do Carmo Rego MA, Pinto PC, da Motta MS, Calixto C. Perinatal or earlyposnatal cytomegalovirus infection in preterm infants under 34 weeks gestation born to CMV-seropositive mothers within a high-seroprevalence population. J Pediatr. 2004; 145:685-8. 